\title{
Assessment the Sliding Wear Behavior of Laser Microtexturing Ti6Al4V under Wet Conditions
}

\author{
Juan Manuel Vazquez Martinez ${ }^{1, *(\mathbb{C})}$, Irene Del Sol Illana ${ }^{1} \mathbb{C}$, Patricia Iglesias Victoria ${ }^{2} \mathbb{C}$ and \\ Jorge Salguero ${ }^{1}$ (1) \\ 1 Department of Mechanical Engineering \& Industrial Design, Faculty of Engineering, University of Cadiz, \\ Av. Universidad de Cadiz 10, E-11519 Puerto Real-Cadiz, Spain; irene.delsol@uca.es (I.D.S.I.); \\ jorge.salguero@uca.es (J.S.) \\ 2 Department of Mechanical Engineering, Rochester Institute of Technology, 72 Lomb Memorial Drive, \\ Rochester, NY 14623, USA; pxieme@rit.edu \\ * Correspondence: juanmanuel.vazquez@uca.es; Tel.: +34-956-483-513
}

Received: 19 December 2018; Accepted: 22 January 2019; Published: 24 January 2019

\begin{abstract}
Laser micro-texturing processes, compared to untreated surfaces, can improve the friction, wear and wettability behavior of sliding parts. This improvement is related to the micro-geometry and the dimensions of the texture which is also dependent on the processing parameters. This research studied the effect of laser textured surfaces on the tribological behavior of titanium alloy Ti6Al4V. The influence of processing parameters was analyzed by changing the scanning speed of the beam and the energy density of pulse. First, the characterization of dimensional and geometrical features of the texturized tracks was carried out. Later, their influence on the wetting behavior was also evaluated through contact angle measurements using water as a contact fluid. Then, the tribological performance of these surfaces was analyzed using a ball-on-flat reciprocating tribometer under wet and dry conditions. Finally, wear mechanisms were identified employing electronic and optical microscopy techniques capable to evaluate the wear tracks on Ti surfaces and WC-Co spheres. These analyses had determined a strong dependence between the wear behavior and the laser patterning parameters. Wear friction effects were reduced by up to a 70\% replacing conventional untreated surfaces of Ti6Al4V alloy with laser textured surfaces.
\end{abstract}

Keywords: surface modification; laser texturing; wetting behavior; Ti6Al4V; surface characterization; tribology; wear behavior

\section{Introduction}

Surface modification of metallic surfaces has shown an important growth of engineering applications in recent years. With relevant developments in the fields of aerospace, energy and biomedical industries. The surface modification based on texturing processes is mainly employed for enhancing physic-chemical properties of the substrate material [1-8]. This kind of techniques represents an essential tool to improve the functional performance of specific alloys in working environments, through the variation of specific features as wetting or tribological behavior [9-15]. By using laser surface processing procedures regular or random texture patterns can be achieved [13,16-21]. Laser texturing techniques can be used to induce a large variety of topographies in terms of the distribution and geometry of the irradiated pattern being the most common linear, circular and pulses array distributions $[13,16,19,21]$. Due to this fact, it is known that the geometrical and dimensional characteristics of the generated structures have a direct influence with the contact angle between the liquid and solid phases, resulting in higher or lower water retention capability $[13,19,22-26]$. 
Texturing geometries may act as wear debris traps and water reservoirs, thereby improving the performance under tribological applications of surfaces. Under these conditions, these textures mainly help remove wear debris from the sliding track, also reducing the involved abrasive effects of the detached particles. Moreover, laser processing shows some relevant advantages regarding chemical and mechanical processes. On one hand, the laser system can be adapted to a wide range of parameters for the texturing process, become a more flexible tool than machining operations for surface modification operations. These kinds of treatments, based on laser irradiation under air atmosphere, are usually performed without lubricants or coolant fluids, being environmentally friendly regarding chemical and conventional machining [2,27-29].

Ultra short laser pulses are typically used for metal surface texturing, resulting in melting and vaporizing the material. This technique is mainly employed to remove selective material and obtaining well defined textured patterns. An additional benefit of the ultra-short laser pulses (i.e., picosecond or even femtosecond) is the prevention of material pile-up around the edges of the textured features (pockets). However, this type of laser systems has important disadvantages, such as low resistance to industrial environments and high costs, which makes it difficult to integrate into real life applications [21,30-32]. However, they have been recently integrated into the manufacturing process for specific applications $[33,34]$. The use of conventional laser marking systems for the textures development, usually rejected for this purpose due to their requirement of use in pulse mode, imply a high understanding of the influence of laser processing parameters on the resulting texture features. For linear textures, energy density of pulse $\left(E_{\mathrm{d}}\right)$ and scanning speed of the beam $\left(V_{\mathrm{s}}\right)$ are shown as two of the most relevant parameters involved in the size and geometrical properties of the laser grooves [35-38].

Titanium alloys are commonly used, among others, for the manufacturing of aerospace parts or biomedical components mainly due to their good ratio between weight and mechanical properties and excellent biocompatibility. The use of laser texturing treatments is focused to overcome functioning limitations, such as poor wear behavior. The unstable frictional response of titanium alloys, coupled with severe wear behavior under certain rubbing conditions, make the use of this type of alloys difficult to apply in real scenario tribological applications [39-41]. Under this consideration, the ability to obtain better liquid retention is showed as one of the most effective ways to improve the friction and sliding behavior. Through the development of textured topographies with specific geometry and size (the retention of water over the surface can be obtained) is possible to maintain control of the liquid film thickness. These effects may be mainly obtained by variations on the roughness of the modified surface layer, also controlled by combinations of laser parameters of the process. Moreover, the manufacture of laser microgrooves can be used as micro-channels for controlling direction and flow rate, additionally improving the corrosion resistance and lubricant conditions [13,42-45]. Additionally, texturing geometries may act as wear debris traps and water reservoirs, thereby improving the performance under tribological applications of surfaces [46].

Based on this background and taking as starting point preliminary studies focused on the water retention of surfaces by microtexturing treatments [19], the aim of this research is to investigate the influence of laser processing parameters on the improvement of tribological wear behavior of Ti6Al4V surfaces under wet conditions. A laser surface treatment using a conventional laser marking system have been presented to develop specific surface patterns of linear tracks on titanium samples. Through variations of $E_{\mathrm{d}}$ and $V_{\mathrm{s}}$ a wide range of topographies with different features have been generated, giving place to variations in the contact angle of water droplets. These water retention changes, mainly achieved through surface finishing, can also impact the frictional response and wear behavior. 


\section{Materials and Methods}

\subsection{Laser Texturing Process}

Initially the base surface roughness was set to $R_{\mathrm{a}}<0.05 \mu \mathrm{m}$ and $R_{\mathrm{z}}<0.15 \mu \mathrm{m}$ by mechanical polishing and cleaned by ether-petroleum 50\% dissolution. Textured specimens of $10 \times 10 \mathrm{~mm}^{2}$ side and $5 \mathrm{~mm}$ thickness were performed on Ti6Al4V titanium plates using a using a Ytterbium fiber infrared laser (1070 $\pm 5 \mathrm{~nm}$ wavelength), model Rofin EasyMark F20 system (ROFIN-SINAR Technologies Inc., Plymouth, MI, USA). Spot diameter and pulse width were fixed to $60 \mu \mathrm{m}$ and $100 \mathrm{~ns}$ respectively. The treatments were performed under an open-air atmosphere. Textured surfaces were developed through bidirectional parallel lines. There was no overlapping and the distance between the laser tracks was $0.1 \mathrm{~mm}$.

In order to evaluate the influence of laser processing parameters on the variation of the properties and features of the textured surfaces, different treatments conditions were studied. Three different energy density of pulse $\left(E_{\mathrm{d}}\right)$ were chosen and combined with eight scanning speed of the beam $\left(V_{\mathrm{s}}\right)$, values are shown in Table 1. In total, 24 different textures were characterized for wettability behavior and surface roughness. 12 of these samples corresponding to $10,40,100$ and $250 \mathrm{~mm} / \mathrm{s}$ of $V_{\mathrm{s}}$, plus the non-textured specimen, selected to perform the tribological tests.

Table 1. Laser processing parameters.

\begin{tabular}{cc}
\hline$E_{\mathrm{d}}\left(\mathrm{J} \mathrm{cm}^{-2}\right)$ & $V_{\mathrm{s}}\left(\mathrm{mm} \mathrm{s}^{-1}\right)$ \\
\hline $17.68-7.07-4.42$ & $10-20-40-80-100-150-200-250$ \\
\hline
\end{tabular}

\subsection{Textured Surfaces Characterization}

The effects of texturing parameters are evaluated through the characterization of the treated surfaces. Surface roughness measurements of all the textured surfaces were performed, choosing $R_{\mathrm{z}}$ and $R_{\mathrm{Sm}}$ [41] as control parameters. $R_{\mathrm{z}}$ parameter is defined as the maximum height between deeper and higher values of the asperities contained in the roughness profile during an evaluation length and $R_{\mathrm{Sm}}$ is described as the mean width of the profile elements [47]. These measurements were carried out employing a Mahr Perthometer Concept PGK120 (Mahr technology, Göttingen, Germany) surface profilometer. Scanning electron microscopy (SEM) techniques were also used to analyze the shape of the laser tracks. Additionally, the presence of oxidation on the customized surfaces was studied through energy dispersive spectroscopy (EDS) analysis.

The wetting properties of the modified surfaces play an important role in the improvement of the friction behavior under wet conditions $[16,18]$. For this reason, water retention ability of the different textures was evaluated measuring the contact angle between solid and liquid phases. A Ramé-Hart system (Ramé-hart Instrument Co., Succasunna, NJ, USA) and DropImage Advanced, as image processing software, were used for this purpose.

\subsection{Pin-On-Flat Tribological Tests}

Friction and sliding contact behaviors were evaluated by means of pin-on-flat reciprocating tests. Developed textures were tested against $1.5 \mathrm{~mm}$ diameter tungsten carbide balls. For each condition of the treated specimens, at least two repeated tests were performed applying a maximum Hertz contact pressure of $2.71 \mathrm{GPa}$, which corresponds to a medium Hertz contact pressure of $1.81 \mathrm{GPa}$. Total sliding distance and linear speed were fixed at $50 \mathrm{~m}$ and $0.012 \mathrm{~m} \mathrm{~s}^{-1}$ respectively. The reciprocating stroke length was initially set to $2 \mathrm{~mm}$. All the reciprocating tests were conducted under dry and wet conditions. Water volume was set up on 15-20 $\mu \mathrm{L}$ for lubricating the laser textures in one single dose supplied at the beginning of the tests, and ensure a boundary condition regime. 


\subsection{Frictional Characterization of Test Specimens}

Wear effects and dimensions on the sliding track, as well as the carbide balls used as pins, were evaluated by optical microscopy techniques using an Olympus SZX12 system (Olympus, Tokyo, Japan). Wear track and wear volume $\left(V_{\mathrm{f}}\right)$ caused by the sliding process on the modified surfaces were evaluated using Equation (1) [48] instead of using ASM standard [49]. This standard may not be recommended for textured samples due to its lack of surface uniformity and its difficulty obtaining a reference plane.

$$
V_{\mathrm{f}}=L_{\mathrm{s}}\left[R^{2} \times \sin ^{-1}\left(\frac{W_{\mathrm{t}}}{2 \times R_{\mathrm{f}}}\right)-\left(\frac{W_{\mathrm{t}}}{2}\right)\left(R_{\mathrm{f}}-h_{\mathrm{f}}\right)\right]+\pi \frac{\left(L-L_{\mathrm{s}}\right)}{3 W_{\mathrm{t}}}\left[h_{\mathrm{f}}^{2}\left(3 R_{\mathrm{f}}-h_{\mathrm{f}}\right)\right]
$$

where $L_{\mathrm{s}}$ is the stroke length, $W_{\mathrm{t}}$ is the average of 16 repeated measures of track width, $L$ is the complete track length, $R_{\mathrm{f}}$ is the pin radio and $h_{\mathrm{f}}$ is the wear depth. In this case, $h_{\mathrm{f}}$ can be obtained by Equation (2).

$$
h_{\mathrm{f}}=R_{\mathrm{f}}-\sqrt{R_{\mathrm{f}}^{2}-\frac{W_{\mathrm{t}}^{2}}{4}}
$$

The wear tracks from all tribological tests were also analyzed employing a scanning electron microscopy (SEM) (Tescan Mira3, Brno-Kohoutovice, Czech Republic), and energy dispersive X-ray spectroscopy (EDX) (Tescan Mira3, Brno-Kohoutovice, Czech Republic) with the aim to evaluate the friction effects caused by the sliding motion. In which regards the worn pin area, the adhesion properties of the balls were characterized and measured through the image processing tools previously described. Adhesion shape was approximated to an ellipsoid to calculate it area.

\section{Results and Discussion}

\subsection{Surface Finish of the Textures}

The laser texturing process can create a modified layer with various topographies for specific applications. Through variations of laser processing parameters, the dimensions and geometry of the texturing tracks can be controlled. $V_{\mathrm{s}}$ was shown to be one of the main variables that govern laser surface modification in terms of microgeometrical texture generation, as can be observed in Figures 1 and 2.

The analysis of $R_{\mathrm{z}}$ measurements from the textured surfaces shows that a higher $E_{\mathrm{d}}$ may produce specific topographies with longer asperity dimensions. It does not seem to be a significant dependency or correlation between $R_{\mathrm{z}}$ and $V_{\mathrm{s}}$. However, lower $E_{\mathrm{d}}\left(E_{\mathrm{d}}=4.42 \mathrm{~J} \mathrm{~cm}^{-2} ; E_{\mathrm{d}}=7.07 \mathrm{~J} \mathrm{~cm}^{-2}\right)$ present an inflection point at $V_{\mathrm{s}}=150 \mathrm{~mm} \mathrm{~s}^{-1}$, where the decreasing trend changes to an increasing one. This singular point is caused as a result of the Ti cooling process; the Ti cooled down at the top of the surface obtruding the laser grooves and producing a smother surface. This obstruction is mainly due to a solidification stage in the surface section of vaporized material from the bottom of the textured groove [37].

Regarding $R_{\mathrm{Sm}}$ roughness parameter behavior, a direct influence of $V_{\mathrm{S}}$ was confirmed. As it can be observed in Figure 2, for laser texturing speeds $V_{\mathrm{s}}$ below $80-100 \mathrm{~mm} \mathrm{~s}^{-1}$, a significant trend in the uniformity of the distance between peaks have been found. This effect is mainly caused by the lack of overlapping phenomena between laser textured tracks, allowing to maintain a constant distance between bidirectional parallel lines of the beam.

A significant decrease in the peak distance was detected for $E_{\mathrm{d}}=7.07 \mathrm{~J} \mathrm{~cm}^{-2}$, which is believed to be caused by the particular geometrical formation developed in the cooling process. 

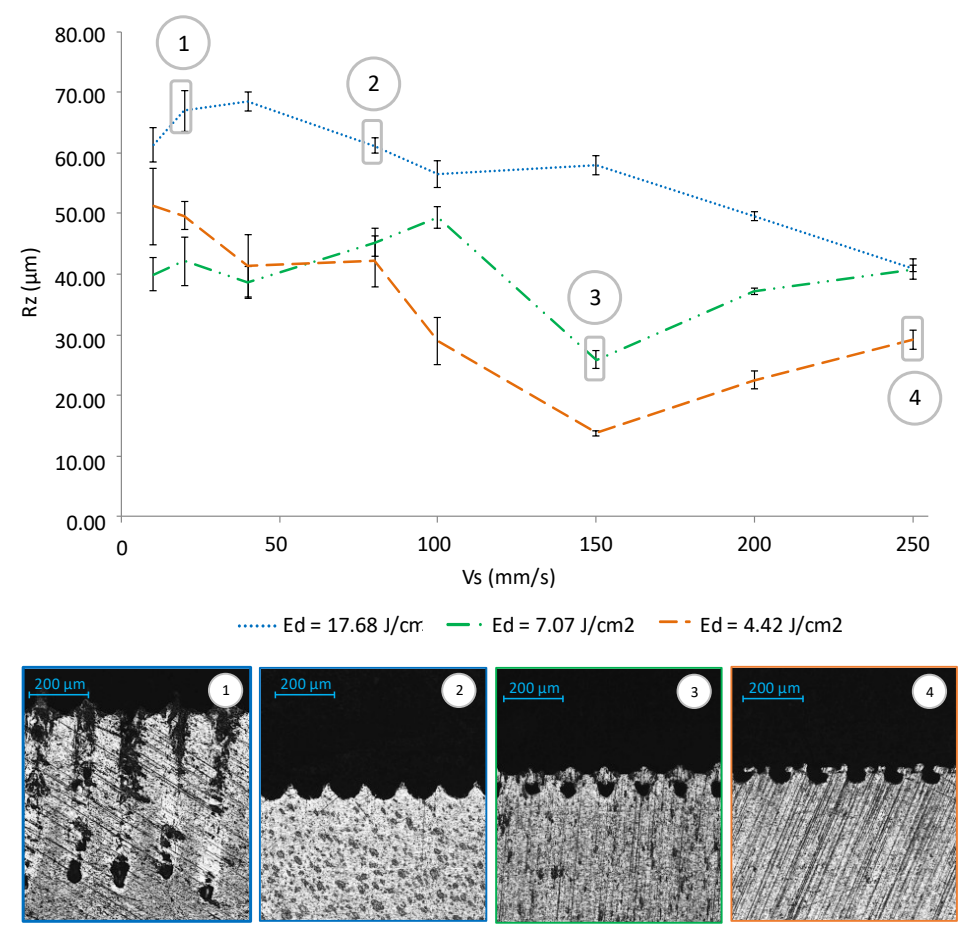

Figure 1. Roughness $R_{\mathrm{z}}$ behavior as a function of $V_{\mathrm{s}}$.
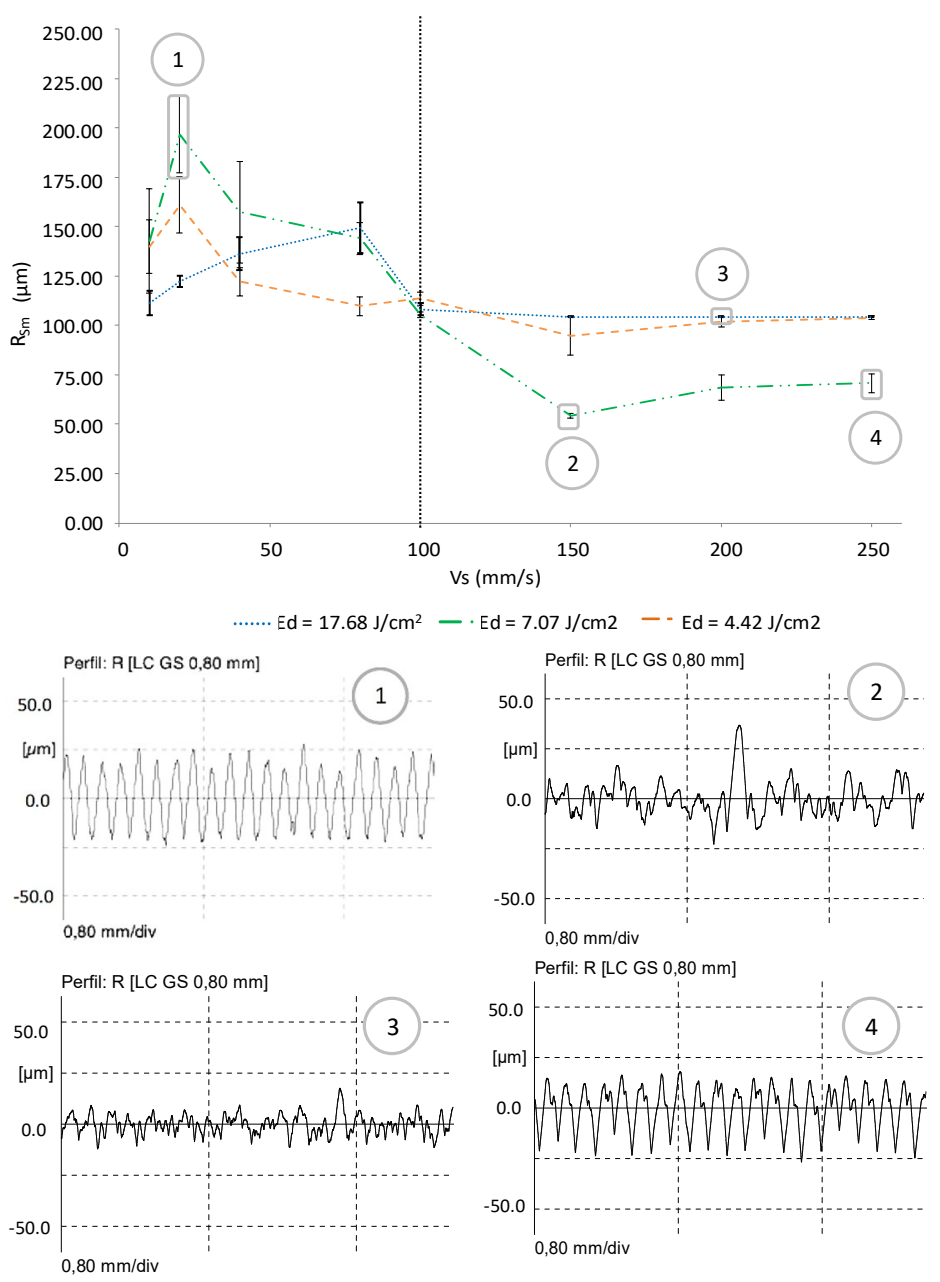

Figure 2. Roughness $R_{\mathrm{Sm}}$ behavior as a function of $V_{\mathrm{s}}$. 


\subsection{Wetting Behavior of the Textured Surfaces}

In this research, the ability to maintain control of the water retention proved to be a relevant aspect in order to improve the cooling and lubricating conditions for friction and sliding applications. Wettability behavior was investigated for surface topographies of various roughness features. Consequently, a control of the wetting behavior of the specimen was achieved through the variation of the laser processing parameters $\left(E_{\mathrm{d}}, V_{\mathrm{s}}\right)$.

Under these considerations, an important dependency was detected between contact angle measures and $V_{\mathrm{S}}$ for textured surfaces, Figure 3, taking as starting point a value of $46.3^{\circ}$ in the contact angle of the untreated surface. Higher intensity treatments developed under higher $E_{\mathrm{d}}$ and lower $V_{\mathrm{s}}$ resulted in a non-uniform asperity topography. This effect gave rise to an irregular distribution of the contact points on the surface. It also favored the breakage of surface tension between solid and liquid phases. Under these conditions, the absorption of water was promoted and the surface showed a better hydrophilic behavior than the initial alloy.

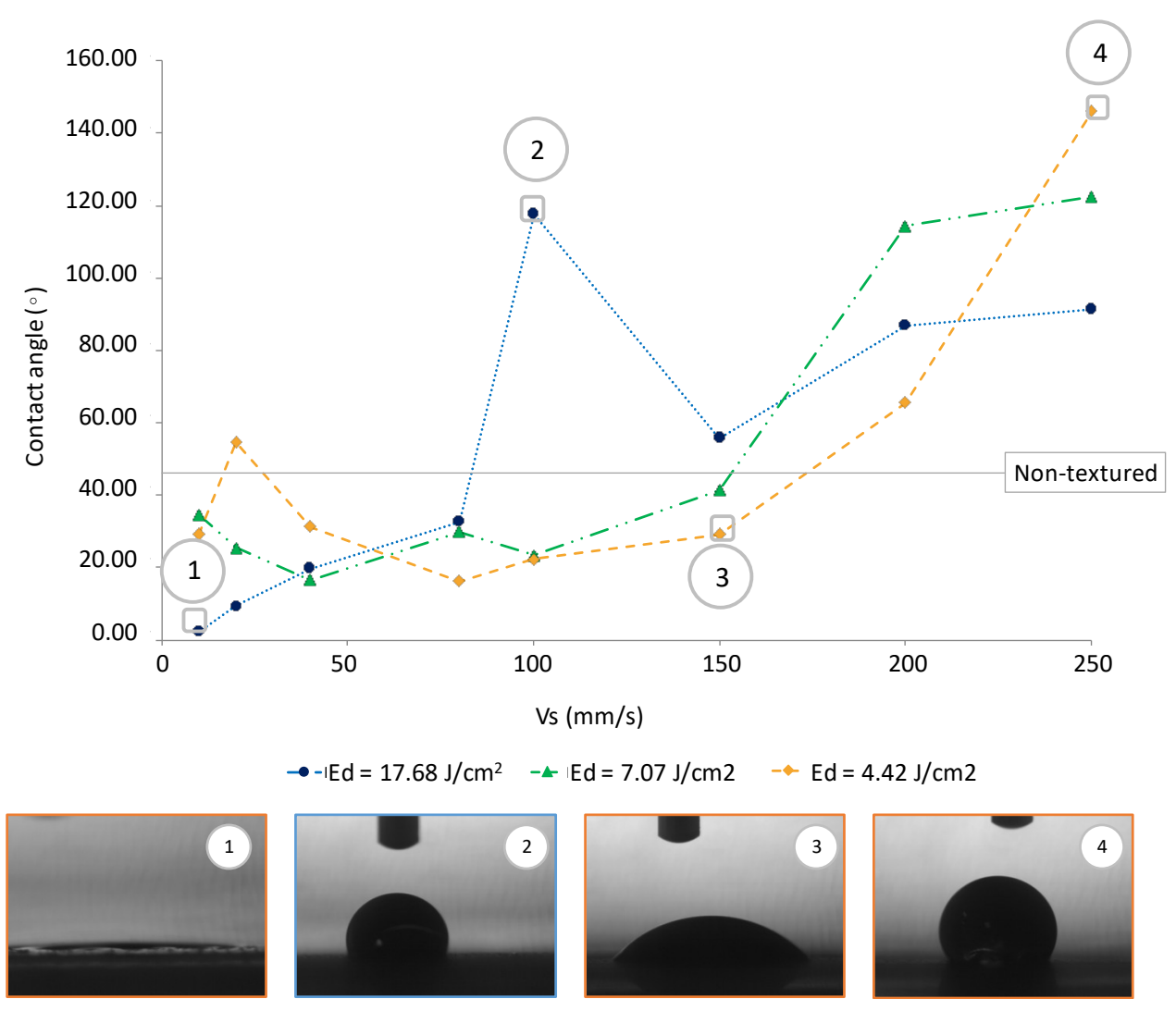

Figure 3. Contact angle as a function of $V_{\mathrm{s}}$

The existence of a singular point was detected under $E_{\mathrm{d}}=17.68 \mathrm{~J} \mathrm{~cm}^{-2}$ and $V_{\mathrm{s}}=100 \mathrm{~mm} \mathrm{~s}^{-1}$ conditions where a significant increase of the contact angle can be observed. It seems to be a relation between the development of texturized grooves with specific dimensions and geometry, and the generation of a uniform and distributed contact between phases.

When $V_{\mathrm{s}}$ was increased, an important growth occurred on the contact angle values, raising the hydrophobic behavior trends of the modified surface. This is especially caused by an increase in the compactness of the treated layer as a result of the development of textures with a higher contact area between different phases [19]. This phenomenon is reproduced under all the range of $E_{\mathrm{d}}$ analyzed in this work. 


\subsection{Friction Coefficient of the Tested Surfaces under Wet Conditions}

Tribological wear behavior under wet conditions should be highly influenced by texturing process parameters as a consequence of wettability behavior. For this reason, hydrophilic surfaces should improve the sliding and cooling features of the contact area.

The evaluation of the textured surfaces by a pin on flat reciprocating tests confirmed a direct dependency between the laser modification process and friction coefficient $(\mu)$, due to its effects on roughness and wettability parameters. Friction coefficient values seemed to get stable from $V_{\mathrm{s}}=$ $100 \mathrm{~mm} \mathrm{~s}^{-1}$ to higher speeds.

On one hand, this behavior is coincident with $R_{\mathrm{Sm}}$ tendency confirming that the distance between texturing grooves influence on the friction and sliding process.

On the other hand, described stability trend is also related to significant growth of the contact angle for $V_{\mathrm{s}}$ higher than $100 \mathrm{~mm} \mathrm{~s}^{-1}$. For these cases, the ability to absorb water was not enough to modify the sliding conditions compared with dry tests. This consideration showed similar behaviors for all the evaluated textures, as shown in Figure 4.

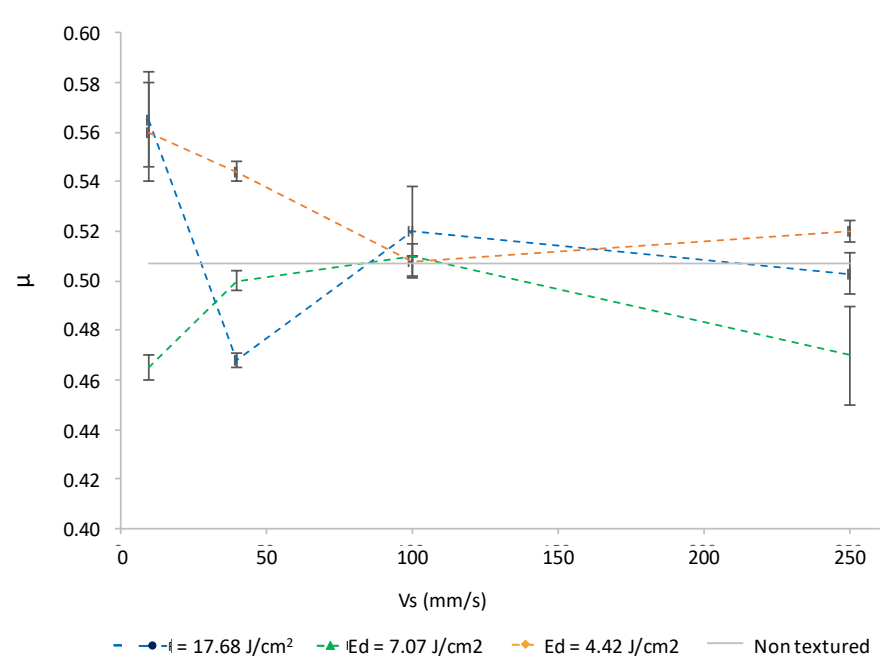

Figure 4. Friction coefficient behavior as a function of $V_{\mathrm{s}}$.

The change of the textured surface as a function of sliding time was analyzed in Figure 5, with the aim to evaluate the durability of the treated surfaces under contact conditions. The lowest $V_{\mathrm{s}}$ was associated to the highest thickness layer and it was taken as a reference. The behaviors of $\mu$ values were analyzed during a test with a duration upper to $2000 \mathrm{~s}$. Growth of the $\mu$ values was identified for non-textured samples, as a result of a progressive increase in the wear effects. Although, laser processed samples maintained a more stable behavior of $\mu$ values during all the test.

Because of this, uniform values of $\mu$ can be observed for the texturized samples in the tribological tests, confirming that this type of samples was not significantly affected by the wear phenomena. This effect is mainly due to the variations in the water absorption properties of the surface, as well as the improvement on the mechanical properties as hardness of the treated layer. However, an increase of the $\mu$ values was detected for the tests with $E_{\mathrm{d}}=17.68 \mathrm{~J} \mathrm{~cm}^{-2}$ and $E_{\mathrm{d}}=4.42 \mathrm{~J} \mathrm{~cm}^{-2}$ textured conditions.

After $1700 \mathrm{~s}$, for low energy density of pulse treatments, an increase in the adhesive effects of the contact pair may appear. This effect results in the generation of a new contact pair with the same material, reducing the friction coefficient. In the case of $20 \mathrm{KHz}$, the thickness of the modified layer is higher than the other treatments increasing the protective effect of the treated area. 


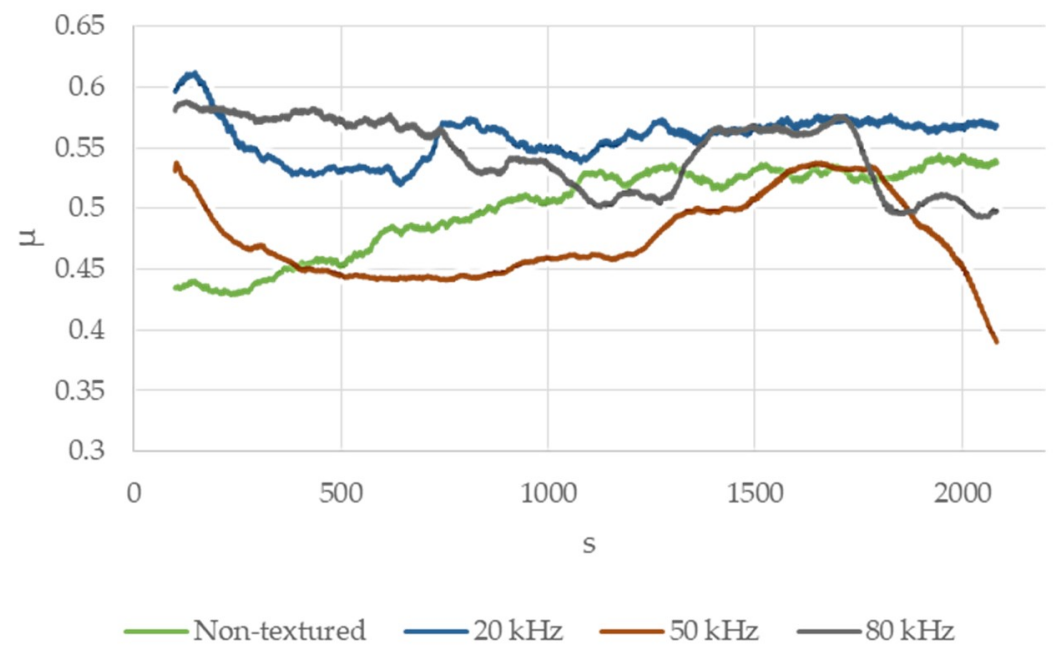

Figure 5. Friction coefficient evolution as a function of sliding time $\left(V_{\mathrm{s}}=10 \mathrm{~mm} / \mathrm{s}\right)$.

\subsection{Wear Behavior of Modified Surfaces}

Wear volume measures were significantly reduced in every textured sample with respect to non-textured conditions, Figure 6 . Wear volume is not just affected by the wettability of the texture, but also by $V_{\mathrm{s}}$ parameter. This control parameter was related to the thermochemical process that produced the oxidation of the surfaces, the possible changes produced on the microstructure of the layer and the thickness of the affected layer $[15,19,36]$. This fact confirmed that laser surface processing results in a protective mechanism of the Ti6Al4V against tribological wear effects.

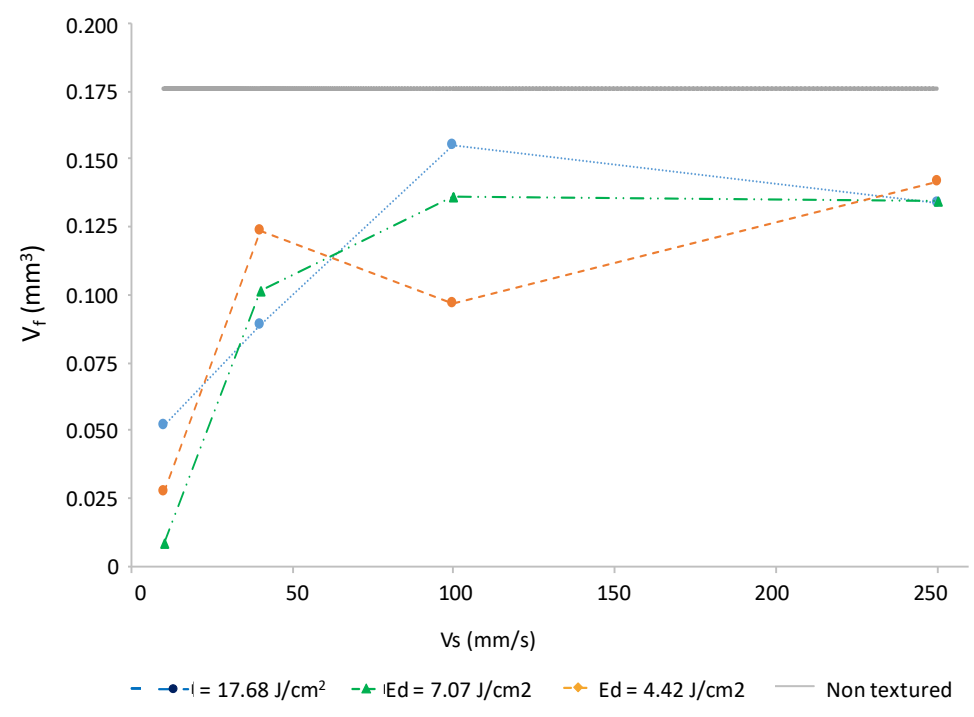

Figure 6. Wear volume evolution as a function of $V_{\mathrm{s}}$.

Wear track analysis allowed to detect an increase of the reversal points of the sliding grove, raising the aggressive effects of the wear on both ends of the track. Over these areas, the carbide sphere experiment acceleration and breaking stages resulted in relevant friction and wear phenomena. In this sense, non-uniform wear tracks were observed for non-textured samples. This fact may develop irregular contact between the carbide sphere and alloy surface, causing an increase of the material worn volume, Figure 7.

For textured surfaces $\left(E_{\mathrm{d}}=17.68 \mathrm{~J} \mathrm{~cm}^{-2}\right)$ the protective effect of the textured surface gives additional uniformity to the wear track, reducing the effects of the carbide balls at the end of the stroke. 


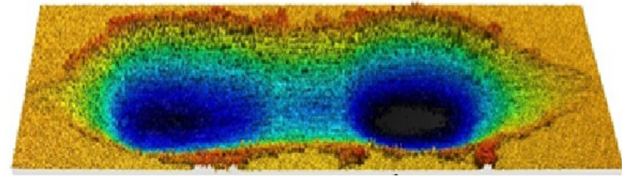

Non - Textured

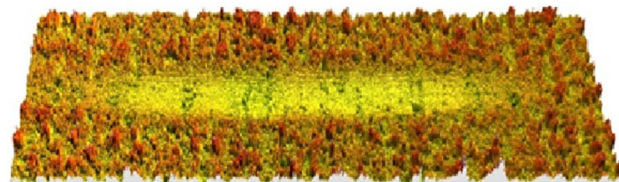

$\mathrm{Ed}=17.68 \mathrm{~J} / \mathrm{cm}^{2} 10 \mathrm{~mm} / \mathrm{s}$

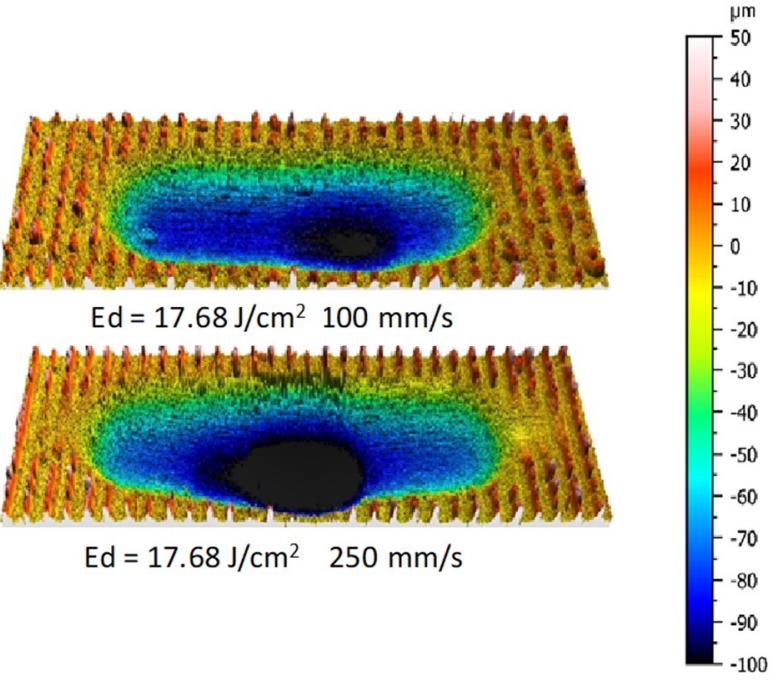

$-100$

Figure 7. Worn morphologies of sliding track as a function of $V_{\mathrm{s}}$.

\subsection{Wear Effects on the Modified Surfaces}

Friction and sliding phenomena over modified surfaces may induce the appearance of different wear mechanisms. The wear behavior of the tribological pair may be conditioned, specially based on the nature of modified surfaces, by modifications of the laser processing parameters.

Taking as starting point the wear effects of non-texturized surfaces, significant abrasive phenomenon was revealed in the bottom of the sliding grooves. This mechanism was mainly characterized by the appearance of scratches and embedded particles over the contact surface. As can be seen on Figure 6, detached particles from the Ti6Al4V surface subjected to cold-working effects became harder than initial alloy, giving rise to three-body abrasion mechanisms. Additionally, material subjected to plastic deformation was found on the external borders of the wear track, as can be seen in Figures 8 and 9 .

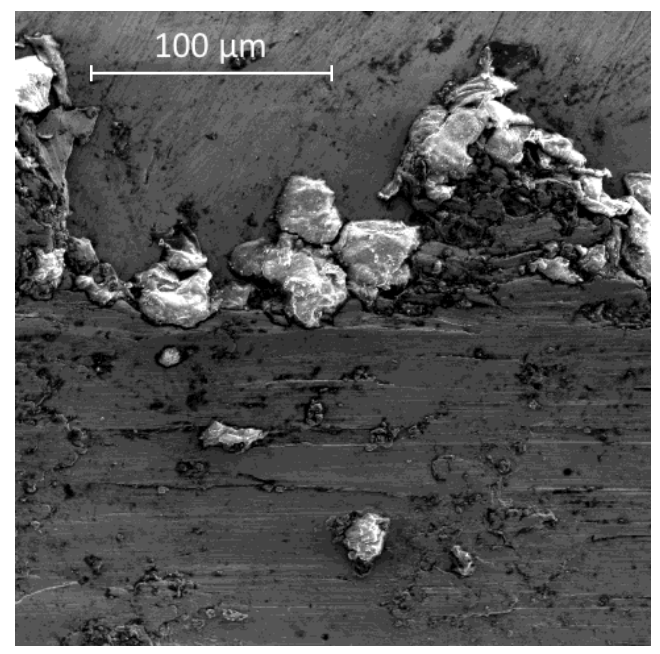

(a)

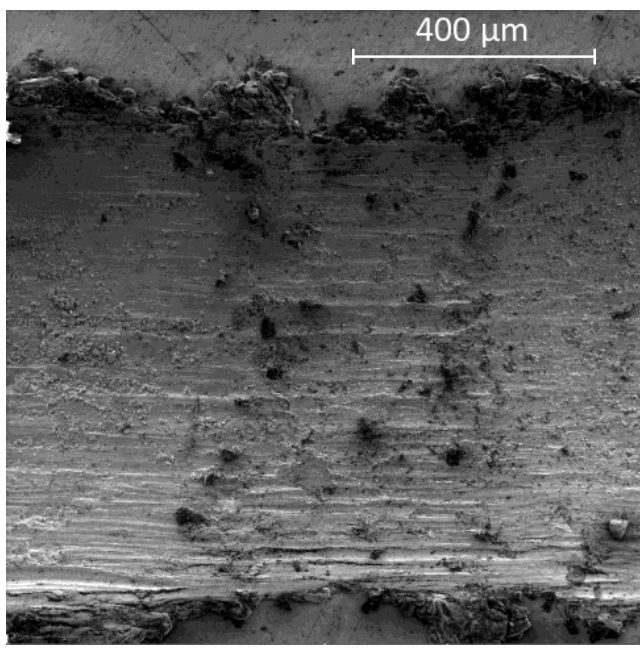

(b)

Figure 8. SEM of the non-textured wear track of Ti6Al4V sample; (a) $750 \times$, (b) $200 \times$. 


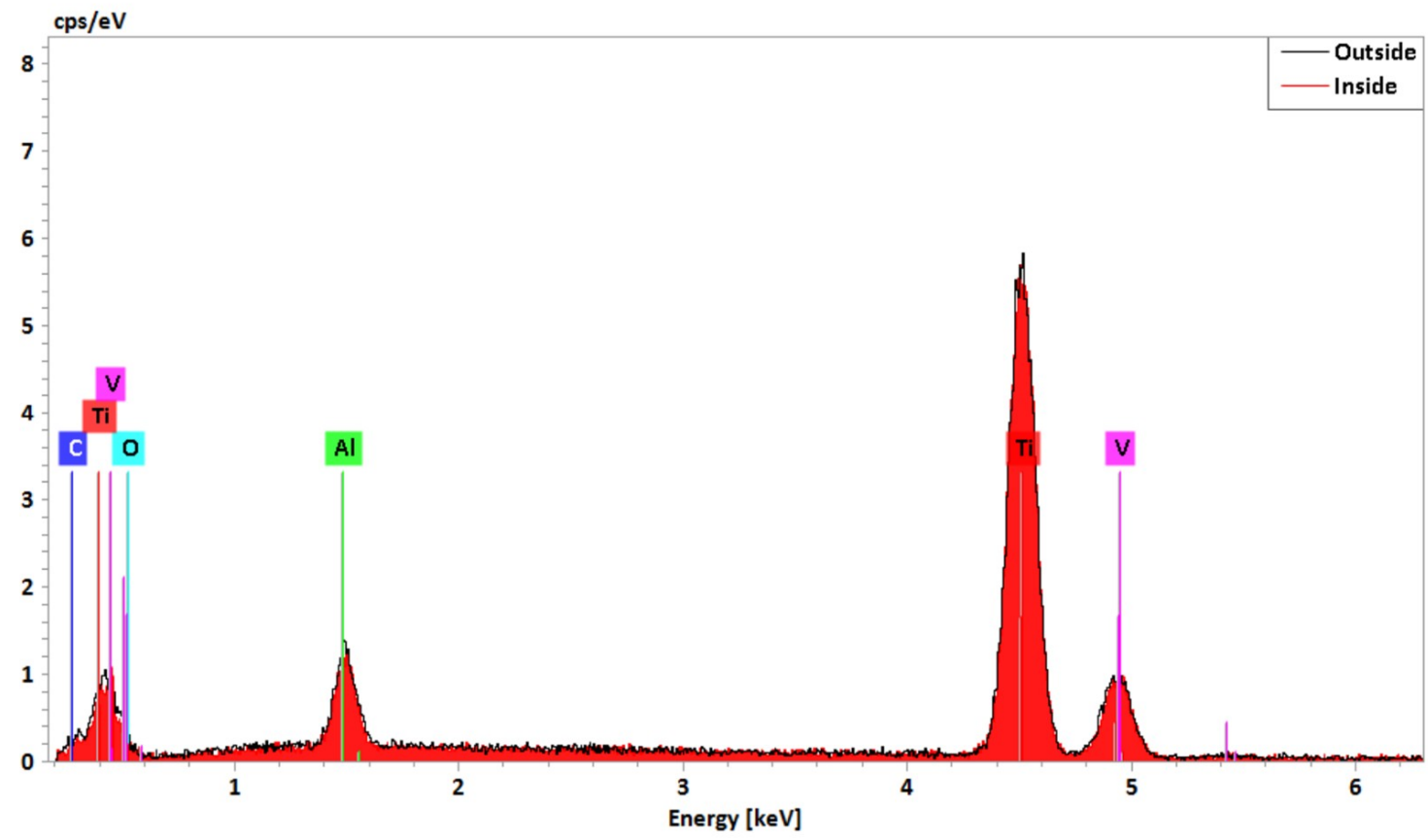

Figure 9. Energy dispersive X-ray spectroscopy (EDX) analysis of the wear track of the non-textured Ti6Al4V sample.

As detailed in a series of preliminary studies $[19,36,37,42]$ the texturized process carried out under air atmosphere results in the appearance of oxidative phenomena. The incidence of oxidation process may induce the increase of hardness of the modified layer, changing the wear effects and the involved mechanisms. With the aim to analyze the influence of the laser treatment under wear conditions behavior of the surfaces, the texturized specimens using $E_{\mathrm{d}}=7.07 \mathrm{~J} \mathrm{~cm}^{-2}$ were chosen as a reference for the evaluation of the $V_{\mathrm{s}}$ effects on the sliding and friction processes.

In this sense, a relevant increase of the thickness of the modified layer can be observed for lower $V_{\mathrm{s}}$ ranges, resulting in variations of the initial surface properties of the alloy. An important reduction of the track width was observed for $V_{\mathrm{s}}=10 \mathrm{~mm} \mathrm{~s}^{-1}$. This consideration was related to the decrease in the worn material volume which was mainly produced by the lowest contact angle between the water droplets and the surface used to evaluate the wetting behavior. This fact confirmed that texturized procedures with enough intensity significantly improve water retention properties of the surface giving rise to a decrease of wear effects.

Functional performance of the modified surfaces was affected by the increase of $V_{\mathrm{s}}$ values. Higher $V_{\mathrm{s}}$ implied the development of thinner layers. As a consequence, an important variation of the wear track width is shown in Figure 10, related to Figure 8 of the untreated specimen. In this situation, abrasive and adhesive mechanisms were observed on the bottom of the sliding groove, Figure 11.

Some extracted particles from the modified layer were harder than the initial alloy mainly due to oxidation. They were placed on the sliding way and caused scratches by the three body abrasion phenomena. Furthermore, the decrease of the contact angle as a function of $V_{\mathrm{s}}$ favored a hydrophobic trend of the textures and the lack of cooling effect provided by water. This fact may be the main cause of temperature increase in the contact area, resulting in the appearance of adhesive mechanism over the wear track and the carbide sphere. The cyclic nature of the adhesive mechanism caused the detachment of WC-Co sphere particles, as can be noticed in the EDX analysis performed on the sliding track, Figures 12 and 13. 


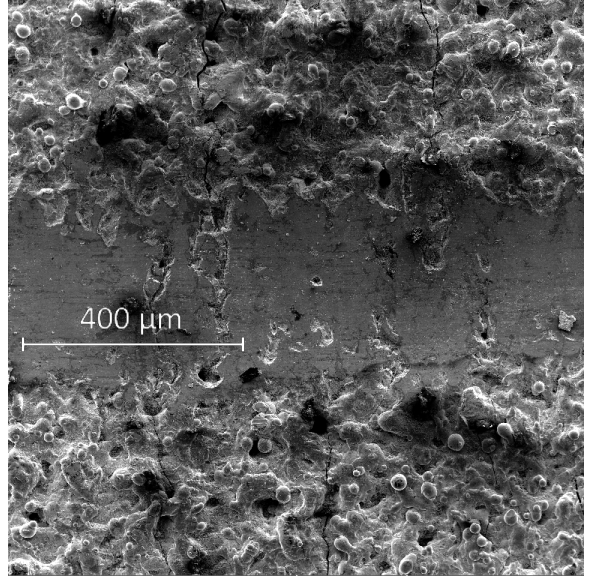

(a)

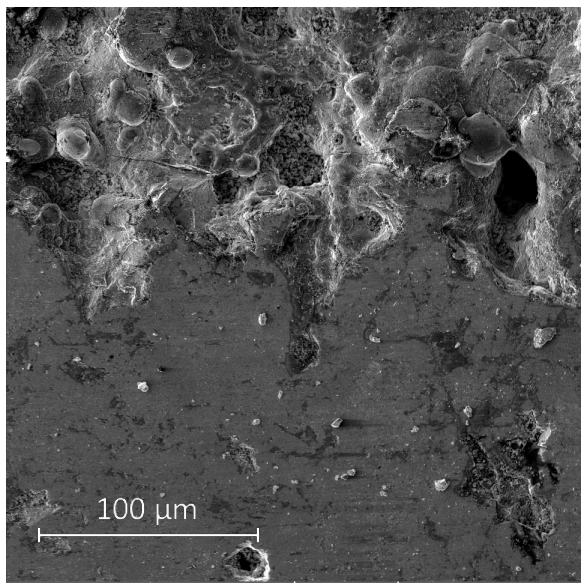

(b)

Figure 10. SEM of the wear track of the $50 \mathrm{~Hz}$ and $10 \mathrm{~mm} \mathrm{~s}^{-1}$ treated sample; (a) $200 \times,(\mathbf{b}) 750 \times$.

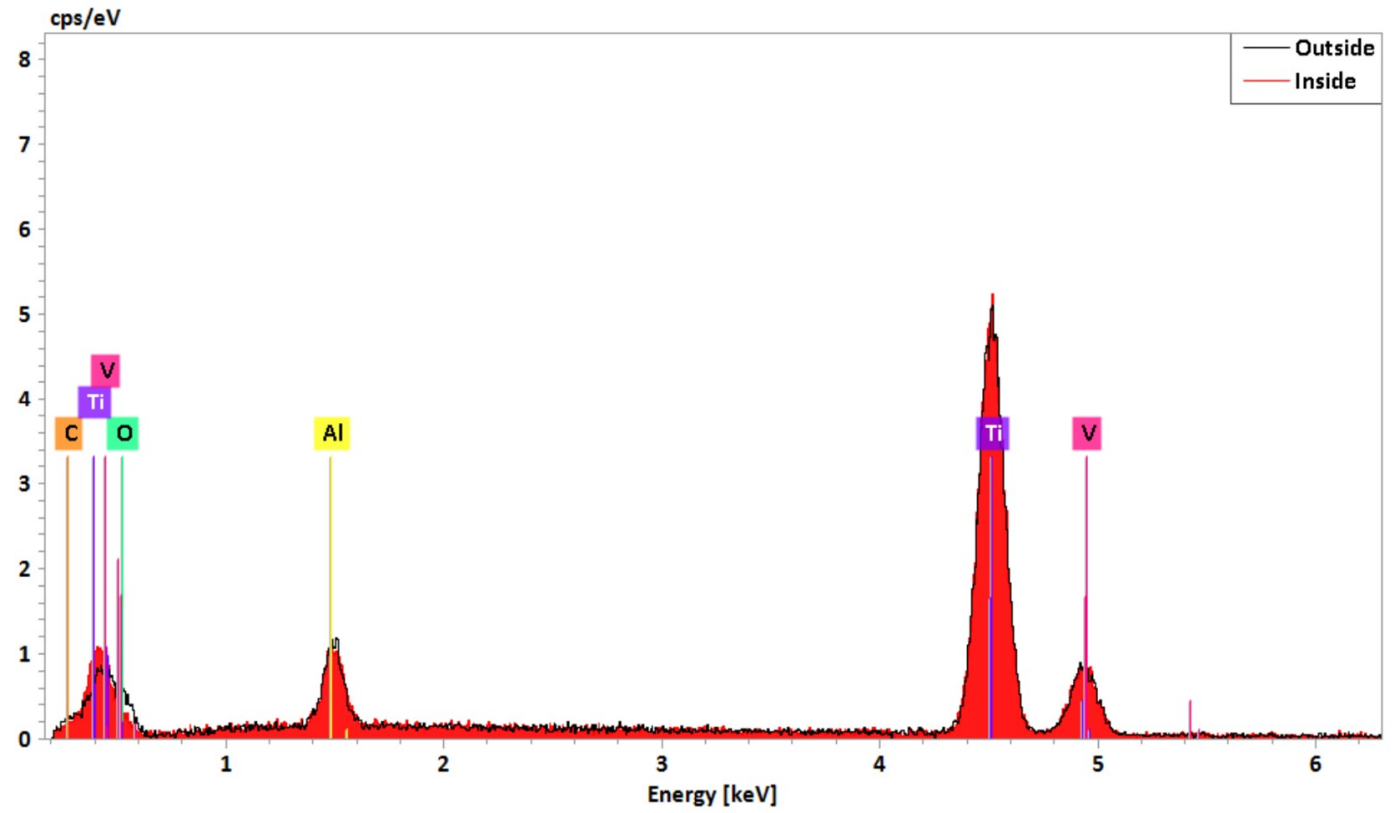

Figure 11. EDX analysis of the wear track of the $50 \mathrm{~Hz}$ and $10 \mathrm{~mm} \mathrm{~s}^{-1}$ treated sample.

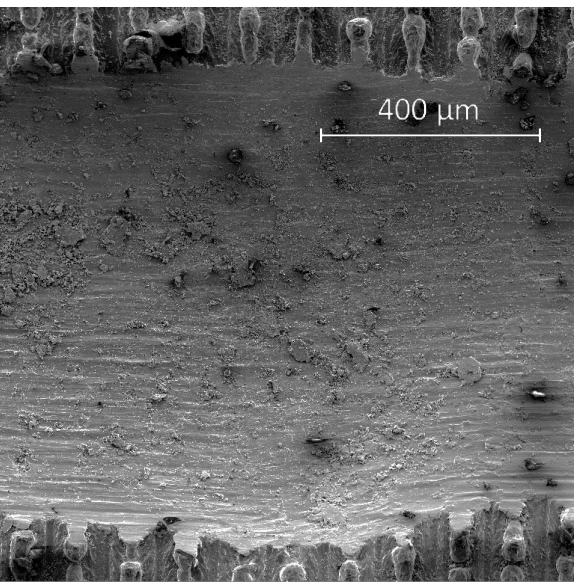

(a)

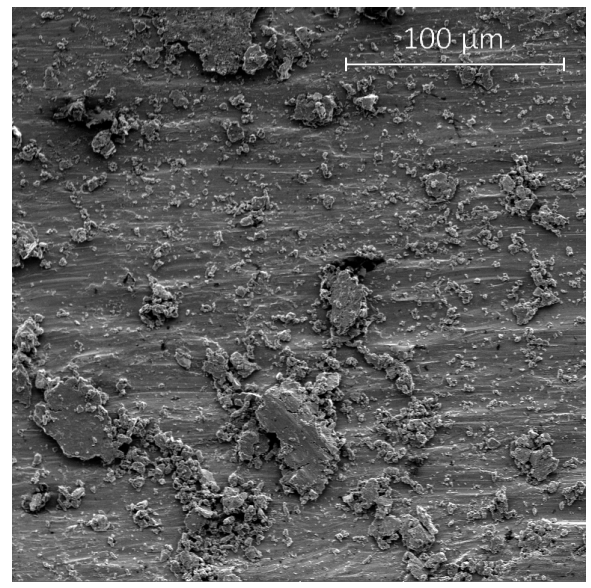

(b)

Figure 12. SEM of the wear track of the $50 \mathrm{~Hz}$ and $100 \mathrm{~mm} \mathrm{~s}^{-1}$ treated sample; (a) $200 \times,(\mathbf{b}) 750 \times$. 


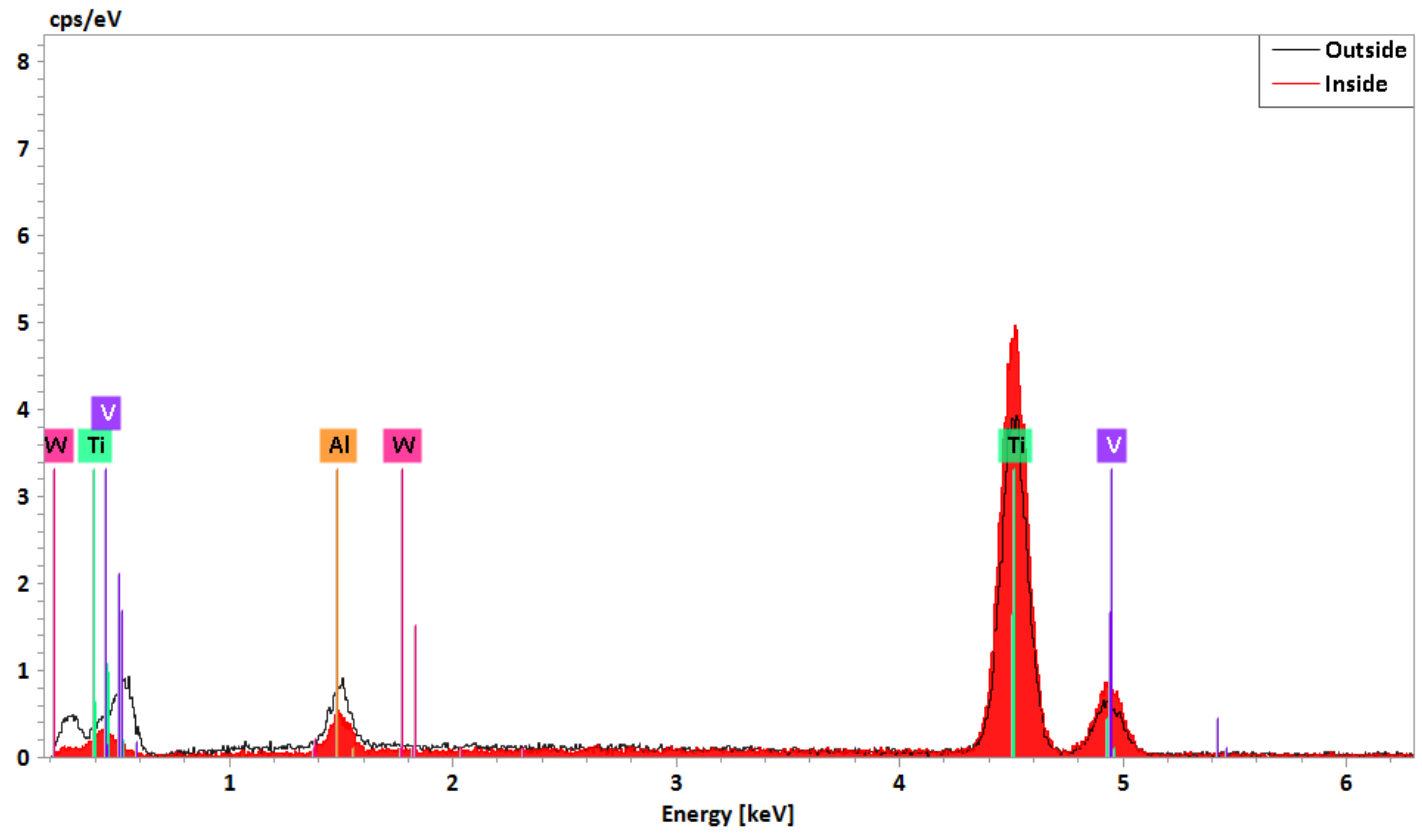

Figure 13. Wear track of the $50 \mathrm{~Hz}$ and $100 \mathrm{~m} \mathrm{~s}^{-1}$ sample EDX analysis.

Regarding carbide spheres, the adhesive mechanism was identified as the main factor affecting friction throughout the tribological tests. Because of this, adhesive behavior of the sphere surfaces is specially related to material worn volume, showing a relevant interest relation between the decrease of wear volume and sliding track width described in previous sections with respect to the adhered area of material on the sphere, Figure 14. This fact can be observed in Figure 15 where a configuration of a laser processing parameter with $V_{\mathrm{s}}=10 \mathrm{~mm} \mathrm{~s}^{-1}$ resulted in smaller areas of increased adhesion on the surface of the carbide sphere, used as pins. Additionally, the increase of $V_{\mathrm{s}}$ is associated to the lack of wetting properties, as well as to the increase of wear volume of the textures, giving rise to higher adhered areas over the pins.

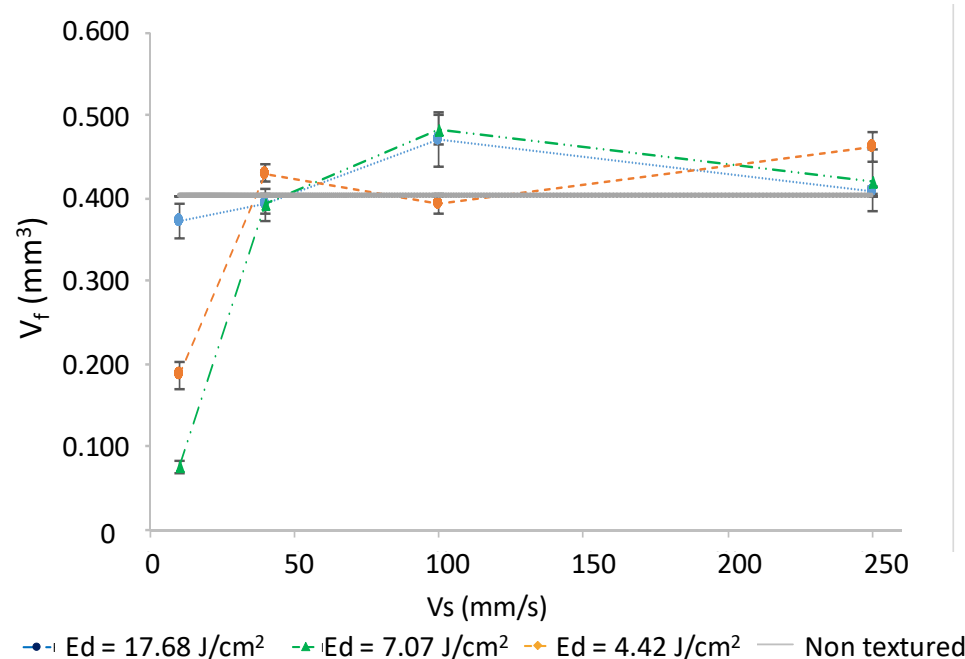

Figure 14. Worn material behavior as a function of $V_{\mathrm{s}}$. 


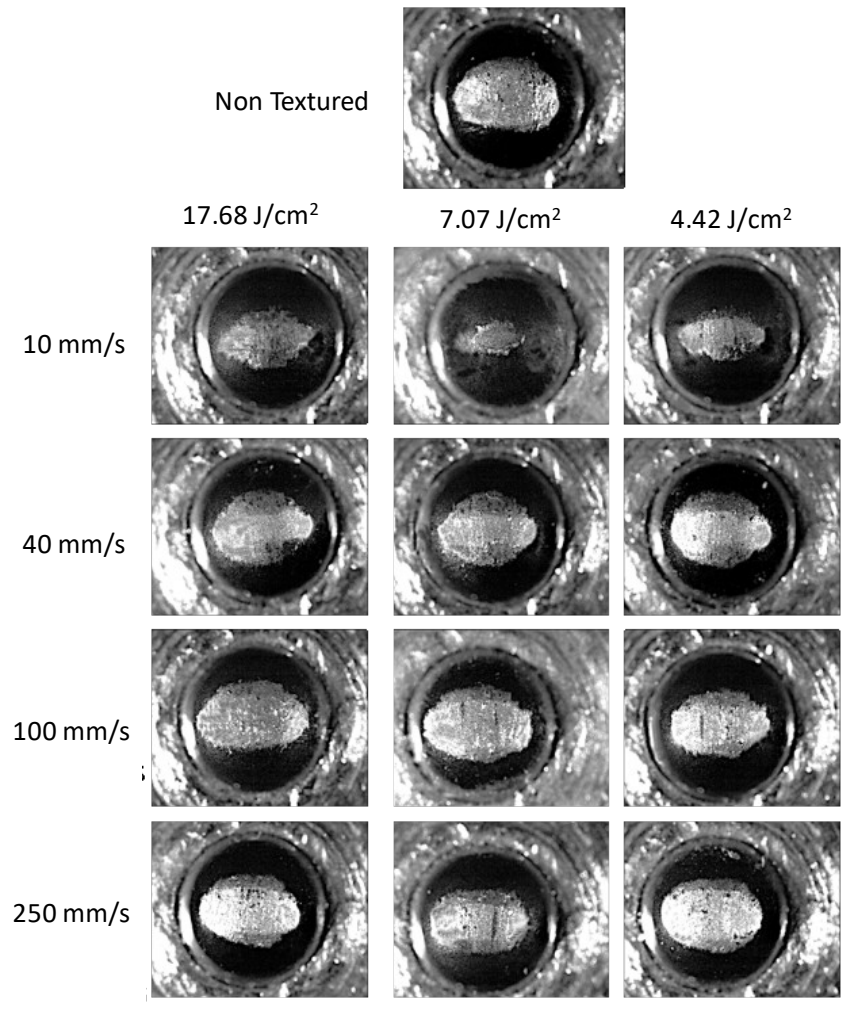

Figure 15. Adhesive wear effects on carbide spheres.

\subsection{Comparative Evaluation between Wet and Dry Tests}

The use of water as a base for lubricant and cooling fluids used in sliding and friction applications may improve the wear behavior of the surfaces. If the wettability properties of the contact area were adapted for higher water retention conditions through the development of micro- channels by the texturing process, the decrease of wear effects was more significant. $V_{\mathrm{S}}\left(10 \mathrm{~mm} \mathrm{~s}^{-1}\right)$ was taken as a reference in the evaluation of friction coefficient of reciprocating tests under wet and dry conditions. It was verified similar trends for the complete sliding range. Friction coefficient under dry and wet conditions is represented in Figure 16. It can be observed that friction coefficient decreased up to 35\%, due to the wettability behavior of the sample.

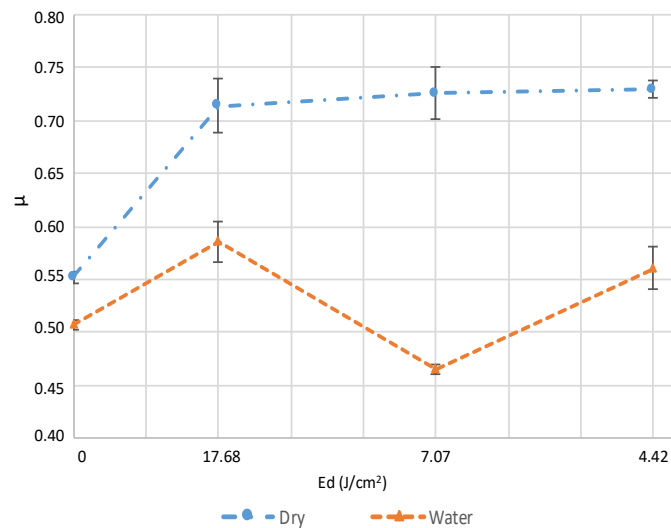

(a)

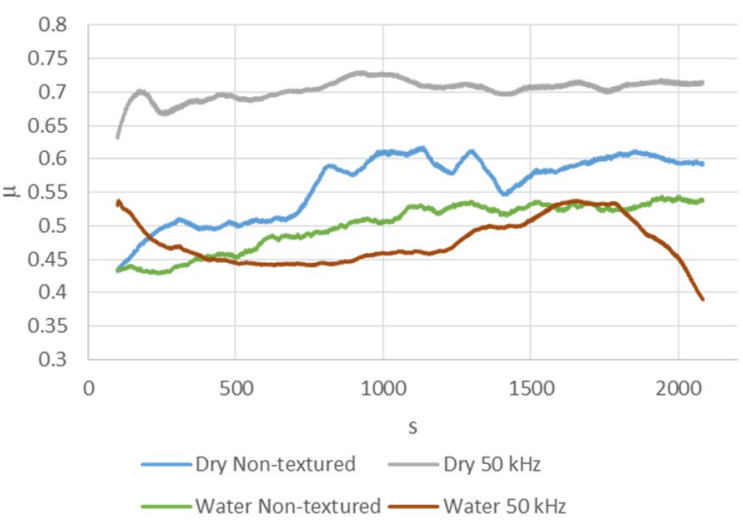

(b)

Figure 16. (a) Friction coefficient as a function of $E_{\mathrm{d}}$ in $V_{\mathrm{s}}=10 \mathrm{~mm} \mathrm{~s}^{-1}$ for wet and dry conditions tests; (b) Friction coefficient as a function of time for wet and dry conditions tests for $E_{\mathrm{d}}=7.07 \mathrm{~J} \mathrm{~cm}^{-2}$ and $V_{\mathrm{s}}=10 \mathrm{~mm} \mathrm{~s}^{-1}$ laser treatment. 
As can be observed in Figure 17, a decrease of the wear track dimensions regarding to a dry test was detected studying the wear effects under wet conditions of texturing surfaces $\left(E_{\mathrm{d}}=7.07 \mathrm{~J} \mathrm{~cm}{ }^{-2}\right.$; $\left.V_{\mathrm{s}}=10 \mathrm{~mm} \mathrm{~s}^{-1}\right)$. In this sense, the use of water may also reduce the volume of worn material in non-textured surfaces, however an adverse effect was observed. Wear track for non-textured surface under wet tribological tests showed a lack of uniformity, in terms of width and depth of the track. This fact could explain the unstable friction coefficient values obtained and shown in Figure 16.

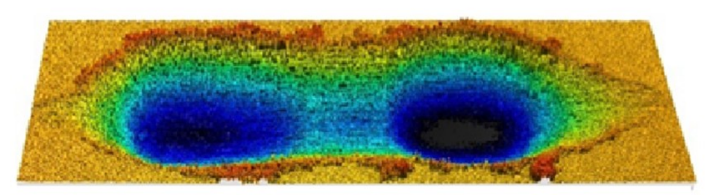

Non-textured + Water

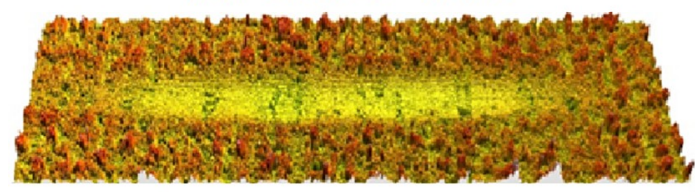

Textured $\left(\mathrm{Ed}=7.07 \mathrm{~J} / \mathrm{cm}^{2} ; \mathrm{Vs}=10 \mathrm{~mm} / \mathrm{s}\right)+$ Water

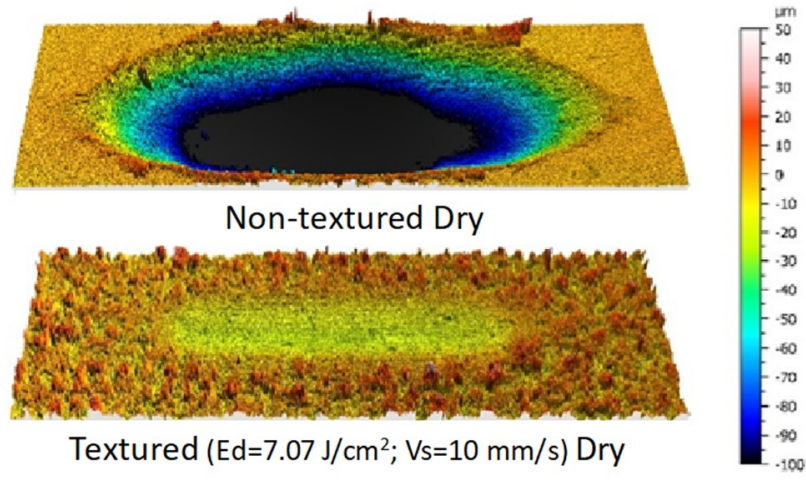

Textured $\left(\mathrm{Ed}=7.07 \mathrm{~J} / \mathrm{cm}^{2} ; \mathrm{Vs}=10 \mathrm{~mm} / \mathrm{s}\right)$ Dry

Figure 17. Effect of texturing treatment on wear track of dry and wet tribological tests.

The width and depth of the sliding track and the associated wear volume could be significantly reduced by the use of laser texturing treatments. This effect is mainly accomplished by the modification of contact area between the tribological pair elements, and the improvements on the surface properties of the alloy, such as hardness and wettability. Under this consideration, a protective function of the modified layer may be considered for friction and sliding applications.

\section{Conclusions}

Laser texturing treatments allow the development of special topographies on the surface of mechanical components. Dimensions and geometry of the texturing tracks can be controlled throughout the laser process, being $V_{\mathrm{s}}$ and $E_{\mathrm{d}}$ the main variables that govern the specific features of micro-textures. For instance, lower incidence of energy, induced by higher $V_{\mathrm{s}}$, results in a decrease of the maximum size and geometrical characteristic of the textured grooves.

Micro-geometrical properties modify the wetting behavior of the surface. Contact angle measured values were increased up to a $300 \%$ compared to the non-textured surfaces for the highest $E_{\mathrm{d}}$ and scanner speed used. However, the specimens textured with the lower $E_{\mathrm{d}}$ and $V_{\mathrm{s}}$ produced a completely hydrophilic surface.

Even though, $R_{\mathrm{Z}}$ values are increased by the laser treatment, friction coefficient values are about $\pm 10 \%$ of the untreated friction coefficient under water conditions. Nevertheless, wear track volume is reduced by up to $70 \%$ by lower $V_{\mathrm{s}}$ treatments $\left(<50 \mathrm{~mm} \mathrm{~s}^{-1}\right)$ concerning to untreated surfaces for all the analyzed ranges of $E_{\mathrm{d}}$ under both conditions, water and dry tests. Furthermore, galling and adhesion effects on the carbide balls are reduced up to more than $90 \%$.

Author Contributions: Conceptualization, J.M.V.M., I.D.S.I. and P.I.V.; Methodology, J.M.V.M., I.D.S.I., P.I.V. and J.S.; Software, I.D.S.I.; Validation, J.M.V.M.; Formal J.M.V.M. and I.D.S.I.; Investigation, J.M.V.M. and J.S.; Resources, J.M.V.M., P.I.V. and J.S.; Writing-Original Draft Preparation, J.M.V.M., and I.D.S.I.; Writing-Review \& Editing, P.I.V. and J.S.; Supervision, J.M.V.M. and J.S.; Project Administration, J.S.; Funding Acquisition, J.S.

Funding: This work has received financial support from the Spanish Government (MINECO/AEI/FEDER, No. DPI2017-84935-R).

Conflicts of Interest: The authors declare no conflict of interest. 


\section{References}

1. Shahali, H.; Jaggessar, A.; Yarlagadda, P.K. Recent advances in manufacturing and surface modification of titanium orthopaedic applications. Procedia Eng. 2017, 174, 1067-1076. [CrossRef]

2. James, A.S.; Thomas, K.; Mann, P.; Wall, R. The role and impacts of surface engineering in environmental design. Mater. Des. 2005, 26, 594-601. [CrossRef]

3. Tian, Y.S.; Chen, C.Z.; Li, S.T.; Huo, Q.H. Research progress on laser surface modification of titanium alloys. Appl. Surf. Sci. 2005, 242, 177-184. [CrossRef]

4. Asri, R.I.M.; Harum, W.S.W.; Samykano, M.; Lah, N.A.C.; Ghani, S.A.C.; Tarlochan, F.; Raza, M.R. Corrosion and surface modification of biocompatible metals: A review. Mater. Sci. Eng. C 2017, 77, 1261-1274. [CrossRef] [PubMed]

5. Weng, F.; Chuanzhong, C.; Yu, H. Research status of laser cladding on titanium and its alloys: A review. Mater. Des. 2014, 58, 412-425. [CrossRef]

6. Biswas, A.; Chatterjee, U.K.; Li, L.; Manna, I.; Majumdar, J.D. Laser assisted surface modification of Ti-6Al-4V for bioimplant application. Surf. Rev. Lett. 2007, 14, 531-534. [CrossRef]

7. Mohammed, M.T.; Khan, Z.A.; Siddiquee, A.N. Surface modification of titanium materials for developing corrosion behavior in human body environment: A review. Procedia Mater. Sci. 2014, 6, 1610-1618. [CrossRef]

8. Wang, D.; Wang, Y.; Wu, S.; Lin, H.; Yang, Y.; Fan, S.; Gu, C.; Wang, J.; Song, C. Customized a Ti6A14V bone plate for complex pelvic fracture by selective laser melting. Materials 2017, 10, 35. [CrossRef]

9. Chan, C.-W.; Lee, S.; Smith, G.; Sarri, G.; Ng, C.-H.; Sharba, A.; Man, H.-C. Enhancement of wear and corrosion resistance of beta titanium alloy by laser gas alloying with nitrogen. Appl. Surf. Sci. 2016, 367, 80-90. [CrossRef]

10. Attar, H.; Ehthemam-Haghighi, S.; Kent, D.; Okulov, I.V.; Wendrock, H.; Bönisch, M.; Volegov, A.S.; Calin, M.; Eckert, J.; Dargusch, M.S. Nanoindentation and wear properties of Ti and Ti-TiB composite materials produced by selective laser melting. Mater. Sci. Eng. A 2017, 688, 20-26. [CrossRef]

11. Sebastian, D.; Yao, C.; Lian, I. Mechanical durability of engineered superhydrophobic surfaces for anti-corrosion. Coatings 2018, 8, 162. [CrossRef]

12. Aniolek, K.; Kupka, M.; Barylski, A. Sliding wear resistance of oxide layers formed on a titanium surface during thermal oxidation. Wear 2016, 356-357, 23-29. [CrossRef]

13. May, A.; Agarwal, N.; Lee, J.; Lambert, M.; Akkan, C.K.; Nothdurft, F.P.; Aktas, O.C. Laser induced anisotropic wetting on Ti-6Al-4V surfaces. Mater. Lett. 2015, 138, 21-24. [CrossRef]

14. Akbarzadeh, A.; Khonsari, M.M. Effect of untampered plasma coating and surface texturing on friction and running-in behavior of piston rings. Coatings 2018, 8, 110. [CrossRef]

15. Cinca, N.; Cygan, S.; Senderowski, C.; Jaworska, L.; Dosta, S.; Cano, I.G.; Guilemany, J.M. Sliding wear behavior of Fe-Al coatings at high temperatures. Coatings 2018, 8, 268. [CrossRef]

16. Ahuir-Torres, J.I.; Arenas, M.A.; Perrie, W.; Dearden, G.; de Damborenea, J. Surface texturing of aluminium alloy AA2024-T3 by picosecond laser: Effect on wettability and corrosion properties. Surf. Coat. Technol. 2017, 321, 279-291. [CrossRef]

17. Matschegewski, C.; Staehlke, S.; Birkholz, H.; Lange, R.; Beck, U.; Engel, K.; Nebe, J.B. Automatic actin filament quantification of osteoblasts and their morphometric analysis on microtextured silicon-titanium arrays. Materials 2012, 5, 1176-1195. [CrossRef]

18. Demir, A.G.; Maressa, P.; Previtali, B. Fibre laser texturing for surface functionalization. Phys. Procedia 2013, 41, 759-768. [CrossRef]

19. Vazquez-Martinez, J.M.; Salguero Gomez, J.; Mayuet Ares, P.F.; Fernandez-Vidal, S.R.; Batista Ponce, M. Effects of laser microtexturing on the wetting behavior of Ti6Al4V alloy. Coatings 2018, 8, 145. [CrossRef]

20. Ancona, A.; Joshi, G.S.; Volpe, A.; Scaraggi, M.; Lugarà, P.M.; Carbone, G. Non-uniform laser surface texturing of an un-tapered square pad for tribological applications. Lubricants 2017, 5, 41. [CrossRef]

21. Ukar, E.; Lamikiz, A.; Martinez, S.; Arrizubieta, I. Laser texturing with conventional fiber laser. Procedia Eng. 2015, 132, 663-670. [CrossRef]

22. Bormashenko, E. Progress in understanding wetting transitions on rough surfaces. Adv. Colloid Interface Sci. 2015, 222, 92-103. [CrossRef] [PubMed]

23. Otitoju, T.A.; Ahmad, A.L.; Ooi, B.S. Superhydrophilic (superwetting) surfaces: A review on fabrication and application. J. Ind. Eng. Chem. 2017, 47, 19-40. [CrossRef] 
24. Belhadjamor, M.; Belghith, S.; Mezlini, S.; El Mansori, M. Effect of the surface texturing scale on the self-clean function: Correlation between mechanical response and wetting behavior. Tribol. Int. 2017, 111, 91-99. [CrossRef]

25. Wojciechowski, L.; Kubiak, K.J.; Mathia, T.G. Roughness and wettability of surfaces in boundary lubricated scuffing wear. Tribol. Int. B 2016, 93, 593-601. [CrossRef]

26. Liang, Y.; Shu, L.; Natsu, W.; He, F. Anisotropic wetting characteristics versus roughness on machined surfaces of hydrophilic and hydrophobic materials. Appl. Surf. Sci. 2015, 331, 41-49. [CrossRef]

27. Attar, H.; Calin, M.; Zhang, L.C.; Scudino, S.; Eckert, J. Manufacture by selective laser melting and mechanical behavior of commercially pure titanium. Mater. Sci. Eng. A 2014, 593, 170-177. [CrossRef]

28. Ali, N.; Bashir, S.; Kalsoom, U.; Akram, M.; Mahmood, K. Effect of dry and wet ambient environment on the pulsed laser ablation of titanium. Appl. Surf. Sci. 2013, 270, 49-57. [CrossRef]

29. Oh, J.M.; Lee, B.G.; Cho, S.W.; Choi, G.S.; Lim, J.W. Oxygen effects on the mechanical properties and lattice strain of Ti and Ti-6Al-4V. Met. Mater. Int. 2011, 17, 733-736. [CrossRef]

30. Lavisse, L.; Jouvard, J.M.; Imhoff, L.; Heintz, O.; Korntheuer, J.; Langlade, C.; Bourgeois, S.; Marco de Lucas, M.C. Pulsed laser growth and characterization of thin films on titanium substrates. Appl. Surf. Sci. 2007, 253, 8226-8230. [CrossRef]

31. Fasai, A.Y.; Mwenifumbo, S.; Rahbar, N.; Chen, J.; Li, M.; Beye, A.C. Nano-second UV laser processed micro-grooves on Ti6Al4V for biomedical applications. Mater. Sci. Eng. C 2009, 29, 5-13. [CrossRef]

32. Xing, Y.; Deng, J.; Gao, P.; Gao, J.; Wu, Z. Angle-dependent tribological properties of AlCrN coatings with microtextures induced by nanosecond laser under dry friction. Appl. Phys. A 2018, 124, 294. [CrossRef]

33. Bonse, J.; Koter, R.; Hartelt, M.; Spaltmann, D.; Pentzien, S.; Höhm, S.; Rosenfeld, A.; Krüger, J. Tribological performance of femtosecond laser-induced periodic surface structures on titanium and a high toughness bearing steel. Appl. Surf. Sci. 2015, 336, 21-27. [CrossRef]

34. Gnilitskyi, I.; Rotundo, F.; Martini, C.; Pavlov, I.; Ilday, S.; Vovk, E.; Ilday, F.O.; Orazi, L. Nano patterning of AISI 316L stainless steel with Nonlinear Laser Lithography: Sliding under dry and oil-lubricated conditions. Tribol. Int. 2016, 99, 67-76. [CrossRef]

35. Mahamood, R.M.; Akinlabi, E.T.; Shukla, M.; Pityana, S. Scanning velocity influence on microstructure, microhardness and wear resistance of laser deposited Ti6Al4V/TIC composite. Mater. Des. 2013, 50, 656-666. [CrossRef]

36. Vrancken, B.; Thijs, L.; Kruth, J.P.; Van Humbeeck, J. Heat treatment of Ti6Al4V produced by selective laser melting: Microstructure and mechanical properties. J. Alloys Compd. 2012, 541, 177-185. [CrossRef]

37. Vázquez Martínez, J.M.; Salguero Gómez, J.; Batista Ponce, M.; Botana Pedemonte, F.J. Effects of laser processing parameters on texturized layer development and surface features of Ti6Al4V alloy samples. Coatings 2018, 8, 6. [CrossRef]

38. Zhao, Y.; Du, H. Effect of laser scanning speed on the wear behavior of nano-SiC-modified Fe/WC composite coatings by laser remelting. Coatings 2018, 8, 241. [CrossRef]

39. Khana, R.; Ong, J.L.; Oral, E.; Narayan, R.J. Progress in wear resistant materials for total hip arthroplasty. Coatings 2017, 7, 99. [CrossRef]

40. Veiga, C.; Davim, J.P.; Loureiro, A.J.R. Properties and applications of titanium alloys: A brief review. Rev. Adv. Mater. Sci. 2012, 32, 133-148.

41. Leuders, S.; Thone, M.; Riemer, A.; Niendorf, T.; Troster, T.; Richard, H.A.; Maier, H.J. On the mechanical behavior of titanium alloy Ti6Al4V manufactured by selective laser melting: Fatigue resistance and crack growth performance. Int. J. Fatigue 2013, 48, 300-307. [CrossRef]

42. Patel, D.S.; Singh, A.; Balani, K.; Ramkumar, J. Topographical effects of laser surface texturing on various time-dependent wetting regimes in Ti6Al4V. Surf. Coat. Technol. 2018, 349, 816-829. [CrossRef]

43. Chen, L.; Liu, Z.; Shen, Q. Enhancing tribological performance by anodizing micro-textured surfaces with nano-MoS 2 coatings prepared on aluminum-silicon alloys. Tribol. Int. 2018, 122, 84-95. [CrossRef]

44. Vlădescu, S.-C.; Olver, A.; Pegg, I.; Reddyhoff, T. The effects of surface texture in reciprocating contacts-An experimental study. Tribol. Int. 2015, 82, 28-42. [CrossRef]

45. AlMangour, B.; Grzesiak, D.; Cheng, J.; Ertas, Y. Thermal behavior of the molten pool, microstructural evolution, and tribological performance during selective laser melting of TiC/316L stainless steel nanocomposites: Experimental and simulation methods. J. Mater. Process. Technol. 2018, 257, 288-301. [CrossRef] 
46. Varenberg, M.; Halperin, G.; Etsion, I. Different aspects of the role of wear debris in fretting wear. Wear 2002, 252, 902-910. [CrossRef]

47. ISO 4287:1997 Geometrical Product Specifications (GPS)—Surface Texture: Profile Method_Terms, Definitions and Surface Texture Parameters; International Organization Standardization (ISO): Geneva, Switzerland, 1997.

48. Qu, J.; Truhan, J.J. An efficient method for accurately determining wear volumes of sliders with non-flat wear scars and compound curvatures. Wear 2006, 261, 848-855. [CrossRef]

49. ASTM G133-05 Standard Test Method for Linearly Reciprocating Ball-on-Flat Sliding Wear; ASTM Standard: West Conshohocken, PA, USA, 2016.

(C) 2019 by the authors. Licensee MDPI, Basel, Switzerland. This article is an open access article distributed under the terms and conditions of the Creative Commons Attribution (CC BY) license (http:/ / creativecommons.org/licenses/by/4.0/). 